\title{
Características Culturais e Severidade da Mancha Foliar de Quambalaria eucalypti Sob Diferentes Regimes de Temperatura, Luz e Período de Molhamento Foliar
}

\author{
Gabriela C.G. Andrade, Acelino C. Alfenas, Reginaldo G. Mafia, Edival A.V. Zauza, \\ Michelle M.F. Couto \& Luiz A. Maffia
}

Departamento de Fitopatologia, Universidade Federal de Viçosa, CEP 36570-000, Viçosa MG, Brasil, e-mail:aalfenas@ufv.br Autor para correspondência: Acelino C. Alfenas

\begin{abstract}
ANDRADE, G.C.G., ALFENAS, A.C., MAFIA, R.G., ZAUZA, E.Â.V., COUTO, M. M.F. \& MAFFIA, L.A. Características culturais e severidade da mancha foliar de Quambalaria eucalypti sob diferentes regimes de temperatura, luz e período de molhamento foliar. Fitopatologia Brasileira 32:329-334. 2007.
\end{abstract}

\section{RESUMO}

Quambalaria eucalypti foi recentemente relatado como agente etiológico da mancha foliar e do anelamento da haste de Eucalyptus spp., no Brasil. Em vista do pouco conhecimento disponível sobre este patossistema, procurou-se, neste trabalho, avaliar o crescimento micelial e a esporulação do fungo em diferentes meios de cultura, determinar "in vitro" a temperatura ótima para o crescimento micelial, esporulação e a germinação de conídios, avaliar a influência do regime de luz sobre a germinação de conídios e determinar a influência do binômio temperatura - tempo de câmara úmida sobre a severidade da doença. As temperaturas de 25,13 e $37^{\circ} \mathrm{C}$ foram respectivamente, ótima, mínima e máxima, para o crescimento. A temperatura ótima para esporulação foi de $25^{\circ} \mathrm{C}$. A interação entre meios de cultura e isolados foi significativa, sendo que os meios de batata-dextrose-ágar (BDA), V8-ágar (V8) e caldo de vegetais-ágar foram os mais favoráveis ao crescimento micelial, seguidos de caseína hidrolizada ágar e ágar água. Todavia, para a esporulação, a interação entre meios de cultura e isolados não foi significativa e o meio de BDA foi o mais favorável à esporulação do patógeno. A temperatura e o regime de luz não afetaram significativamente a germinação de conídios, com uma taxa média de $85 \%$ de germinação. A interação entre temperatura e tempo de permanência em câmara úmida não foi significativa para severidade da doença. O modelo quadrático foi o que melhor representou a severidade em função da temperatura, com ponto ótimo estimado igual a $27^{\circ} \mathrm{C}$. O modelo exponencial foi o que melhor representou a severidade em função do tempo de câmara úmida.

Palavras-chave adicionais: Eucalyptus, temperatura, luz, molhamento foliar, meio de cultura, mancha foliar e anelamento da haste de eucalipto.

\begin{abstract}
Cultural characteristics and severity of the Quambalaria eucalypti leaf spot under different temperatures, light regimes and leaf wetness duration

Quambalaria eucalypti was recently reported as the causal agent of leaf spot and stem curl in Eucalyptus spp. in Brazil. Given the scarcity of knowledge available on this pathosystem our objectives were to evaluate the "in vitro" mycelial growth and sporulation of this fungus in different culture media, determine the optimum temperature of mycelial growth, sporulation and conidial germination, evaluate the influence of the lighting regime on conidial germination and determine the combined influence of time and temperature in a moisture chamber on the disease severity. Temperatures of 25,13 and $37{ }^{\circ} \mathrm{C}$ were found to be the optimum, minimum and maximum for growth, respectively. The optimum temperature for sporulation was $25^{\circ} \mathrm{C}$. The interaction between growth medium and isolates was significant and potato dextrose-agar (PDA), V8-agar (V8) and vegetable broth-agar produced the most mycelial growth, followed by hydrolyzed casein-agar and water-agar. On the other hand, the interaction between culture medium and isolates was not significant for sporulation, although PDA appeared to favor spore production by this pathogen. Temperature and lighting regime did not significantly affect conidial germination, with $85 \%$ of medium rate. The interaction between temperature and time of exposition in a moisture chamber was not significant for severity of disease. A quadratic model best represented disease severity as a function of temperature, with estimated optimum $27^{\circ} \mathrm{C}$. An exponential model best represented disease severity as a function of moisture chamber.
\end{abstract}

Additional keywords: Eucalyptus, temperature, light, leaf wetness, culture media, eucalyptus leaf spot and stem curl.

\section{INTRODUÇÃO}

Atualmente, Quambalaria eucalypti (M.J. Wingf., Crous \& W.J. Swart) Simpson (= Sporothrix eucalypti)

Parte da Tese de Mestrado da primeira autora. Universidade Federal de Viçosa. Viçosa MG. 2004. é um dos principais patógenos do eucalipto em viveiro. A enfermidade por ele incitada, recentemente relatada no Brasil (Alfenas et al., 2001), caracteriza-se por manchas foliares e o anelamento da haste de mudas e de brotações de minicepas, o que pode reduzir conseqüentemente a produção de miniestacas para enraizamento. Sobre as lesões, de coloração marrom a marrom escuras, forma-se, 
na face abaxial, uma massa esbranquiçada de estruturas do fungo. A abundante esporulação seca o torna de fácil disseminação por vento (Alfenas et al., 2004). No campo, além de manchas foliares, o fungo causa também cancro em materiais altamente suscetíveis, como E. globulus Labill., seus híbridos e espécies afins (Alfenas et al., 2001). Há, contudo, ampla variabilidade genética intraespecífica, o que permite a seleção e a clonagem de genótipos-elite resistentes para plantio comercial.

Apesar da importância deste patógeno, pouco se conhece sobre os fatores ambientais que afetam a infecção em eucalipto. Para desenvolver estudos sobre este patossistema, há, contudo, necessidade de se efetuarem inoculações artificiais, o que requer a produção massal de inóculo do patógeno e a determinação prévia das condições favoráveis para o estabelecimento da doença.

O conhecimento das condições favoráveis à infecção e colonização é importante para o estabelecimento de medidas de controle, que visam, em última análise, desfavorecer o patógeno em quaisquer fases do estabelecimento da doença (Agrios, 2004). Os fatores do ambiente determinam a distribuição geográfica, a incidência e a severidade da doença, sendo em muitos casos específicos para o patógeno em questão. Dentre esses fatores, a temperatura é a mais freqüentemente correlacionada com a epidemiologia da doença, seguida pela umidade e luz (Colhoun, 1973).

Em face de seu recente relato no Brasil e dos poucos conhecimentos sobre as características culturais e fatores do ambiente que afetam a infecção de Q. eucalypti no hospedeiro, o presente trabalho objetivou: i) determinar a influência do meio de cultura e da temperatura sobre o crescimento micelial e a esporulação; ii) avaliar o efeito da temperatura e do regime de luz sobre a germinação de conídios; e iii) avaliar os principais fatores (temperatura e duração do período de molhamento foliar) no estabelecimento e desenvolvimento da doença, a fim de embasar estudos epidemiológicos e de controle da enfermidade.

\section{MATERIAL E MÉTODOS}

\section{Efeito da temperatura sobre o crescimento micelial e a esporulação}

Empregou-se o isolado S25 obtido de lesões de um clone híbrido de eucalipto (Eucalyptus maidenii F. Muell. $\mathrm{x}$ E. urophylla Blake). A partir da borda de colônias puras, crescidas em meio batata-dextrose-ágar (BDA) por cinco dias, a $27^{\circ} \mathrm{C}$, e $12 \mathrm{~h}$ de fotoperíodo, retiraram-se discos de cultura de $10 \mathrm{~mm}$ de diâmetro, os quais foram transferidos para o centro de placas de Petri (vidro, PYREX ${ }^{\circledR}$ ) contendo o mesmo meio de cultura. As placas foram mantidas a 7 , $14,21,28,35$ e $42^{\circ} \mathrm{C}$, sob fotoperíodo de $12 \mathrm{~h}(175 \mu \mathrm{E} /$ $\mathrm{m}^{2} /$ seg fornecida por lâmpadas OSRAM ${ }^{\circledR}$ 20W) em câmara de germinação (FANEM ${ }^{\circledR}$, São Paulo, Mod. 347 CDG). O diâmetro das colônias nas diferentes temperaturas foi avaliado diariamente durante 10 dias, com o auxílio de uma régua milimétrica. Ao final deste período, a produção de esporos também foi determinada. Para isso, $10 \mathrm{~mL}$ de água destilada esterilizada foram adicionados em cada uma das placas. A seguir, avaliou-se a concentração de esporos com o auxílio de um hemacitômetro. $\mathrm{O}$ ensaio foi conduzido em delineamento inteiramente casualizado e cada tratamento (temperatura) constituído de cinco repetições, sendo uma placa por repetição.

\section{Crescimento micelial e esporulação em diferentes meios de cultura}

Comparou-se o crescimento micelial radial de três isolados do fungo ( $\mathrm{S} 0$, S8 e S25), nos seguintes meios: batata-dextrose-ágar (BDA), ágar-água (AA), V8-ágar (V8), caseína hidrolizada-ágar a 0,25 \% (CHA) (Dhingra \& Sinclair, 1995) e caldo de vegetais-ágar (CVA) (Pereira et al., 2003). Para tanto, um disco de cultura de $5 \mathrm{~mm}$ de diâmetro e com cinco dias de idade, foi transferido para o centro de uma placa de Petri (vidro, PYREX ${ }^{\circledR}$ ), contendo $20 \mathrm{~mL}$ dos respectivos meios. As placas foram mantidas a $28{ }^{\circ} \mathrm{C}$, sob $12 \mathrm{~h}$ de fotoperíodo $\left(175 \mu \mathrm{E} / \mathrm{m}^{2} / \mathrm{seg}\right)$. Aos 12 dias de incubação, mensurou-se o diâmetro das colônias nos diferentes meios, conforme descrito anteriormente. Após a mensuração, avaliou-se a esporulação em todos os meios de cultivo. Para isso, adicionaram-se $30 \mathrm{~mL}$ de água destilada e esterilizada em cada uma das placas obtendo-se uma suspensão de inóculo. Com auxílio de um hemacitômetro determinou-se o número de esporos $/ \mathrm{mL}$. O experimento foi conduzido em delineamento inteiramente casualizado, com cinco repetições, sendo uma placa por repetição.

\section{Efeito da temperatura e do regime de luz sobre a germinação de conídios}

Neste ensaio, empregaram-se alíquotas de $60 \mu \mathrm{L}$ de uma suspensão aquosa de $10^{5}$ conídios $/ \mathrm{mL}$, obtida a partir de uma cultura pura do fungo em meio V8-ágar, após cinco dias de incubação a $27{ }^{\circ} \mathrm{C}$ sob $12 \mathrm{~h}$ de fotoperíodo (175 $\left.\mu \mathrm{E} \cdot \mathrm{m}^{-2} \cdot \mathrm{s}^{-1}\right)$. A alíquota foi depositada em lâmina escavada, e mantida em câmara úmida, a 15, 18, 21, 24, 27 e $30^{\circ} \mathrm{C}$ e sob $12 \mathrm{~h}$ de fotoperíodo, conforme previamente descrito. Após 24 h, uma gota de lactofenol-azul de algodão foi depositada nas cavidades da lâmina para interromper a germinação dos conídios. A avaliação foi feita contando-se o número de esporos germinados em relação ao número total (200 esporos avaliados por cavidade da lâmina). O delineamento foi o inteiramente casualizado, sendo cada tratamento constituído de três repetições.

Alíquotas preparadas conforme descrito anteriormente foram mantidas a $28{ }^{\circ} \mathrm{C}$ sob os regimes de luz/ausência de luz de 4/20 h, 8/16 h, 12/12 h, 16/8 h, $20 / 4$ h e 24/0 h. Após 24 h, uma gota de lactofenol-azul de algodão foi depositada nas cavidades da lâmina para interromper a germinação dos conídios. Determinou-se ao microscópio ótico o número de esporos germinados em um total de 200 esporos avaliados por cavidade. Cada regime de luz/ausência de luz constituiu um tratamento, o qual foi composto por três repetições. 
Influência do binômio temperatura-tempo de câmara úmida sobre a severidade da doença

Mudas de um clone de eucalipto (E. maidenii x E. urophylla) com 90 dias de idade foram inoculadas utilizandose um atomizador do tipo De Vilbss $n^{\circ}$ 5, com uma suspensão de $10^{5}$ conídios/mL, obtida a partir de colônias do fungo com cinco dias de idade. Após a inoculação, as plantas foram mantidas em câmara úmida a $18,22,26$ e $30^{\circ} \mathrm{C}$ por $0,8,16$, 24, 32 ou 40 h, sob fotoperíodo de 12 h $\left(175 \mu \mathrm{E} \cdot \mathrm{m}^{-2} \cdot \mathrm{s}^{-1}\right)$. Para cada binômio temperatura-tempo de câmara úmida, as plantas foram envolvidas com sacos plásticos sob armação de arame contendo no seu interior algodão umedecido e suas paredes borrifadas com água. Esta armação foi retirada conforme os tempos de câmara úmida pré-determinados. A avaliação da severidade da doença em folhas foi realizada aos 15 dias após a inoculação utilizando-se uma escala diagramática desenvolvida por Andrade (2004). O experimento foi montado em delineamento inteiramente casualizado, em esquema fatorial e com três repetições, sendo uma planta por repetição.

\section{Análises estatísticas}

Os dados de cada ensaio foram submetidos, separadamente, à análise de variância (ANOVA) empregando-se o teste $\mathrm{F}$ ao nível de $5 \%$ de probabilidade. Posteriormente, para as variáveis quantitativas de efeito significativo, procedeu-se o ajuste de modelos de regressão. Os modelos ajustados foram escolhidos com base no valor do coeficiente de determinação $\left(\mathrm{R}^{2}\right)$, pelo significado biológico e com base no gráfico de resíduos. A comparação entre as médias de variáveis qualitativas foi realizada pelo teste de Tukey $(p<0,05)$. As análises estatísticas foram realizadas com auxílio do programa SAEG (Euclydes, 1997).

\section{RESULTADOS}

Efeito da temperatura sobre o crescimento micelial e a esporulação

O crescimento micelial do fungo, determinado pelo diâmetro da colônia (DC), variou significativamente com a temperatura (T) e com o tempo de incubação (TI), sendo representado em uma superfície de resposta. O modelo ajustado foi do tipo quadrático em relação ao efeito da temperatura e linear quanto ao tempo de incubação, sendo definido como: $\mathrm{DC}(\mathrm{mm})=-15,6299+$ $1,6166^{*} \mathrm{~T}\left({ }^{\circ} \mathrm{C}\right)-0,0324 * \mathrm{~T}^{2}+0,0461 * \mathrm{TI}(\mathrm{h})\left(\mathrm{R}^{2}=85 \%\right)$. $\mathrm{O}$ crescimento micelial foi linearmente proporcional com o tempo. As temperaturas estimadas, ótima, mínima e máxima, de crescimento foram de 25,13 e $37{ }^{\circ} \mathrm{C}$, respectivamente (Figura 1). Houve efeito significativo da temperatura sobre a produção de esporos, sendo que a $28{ }^{\circ} \mathrm{C}$ ocorreu maior esporulação. Com base na equação de regressão (modelo quadrático), a temperatura ótima para esporulação foi estimada em $25^{\circ} \mathrm{C}$, com limites inferior e superior iguais a 7 e $42{ }^{\circ} \mathrm{C}$, respectivamente (Figura 2 ).

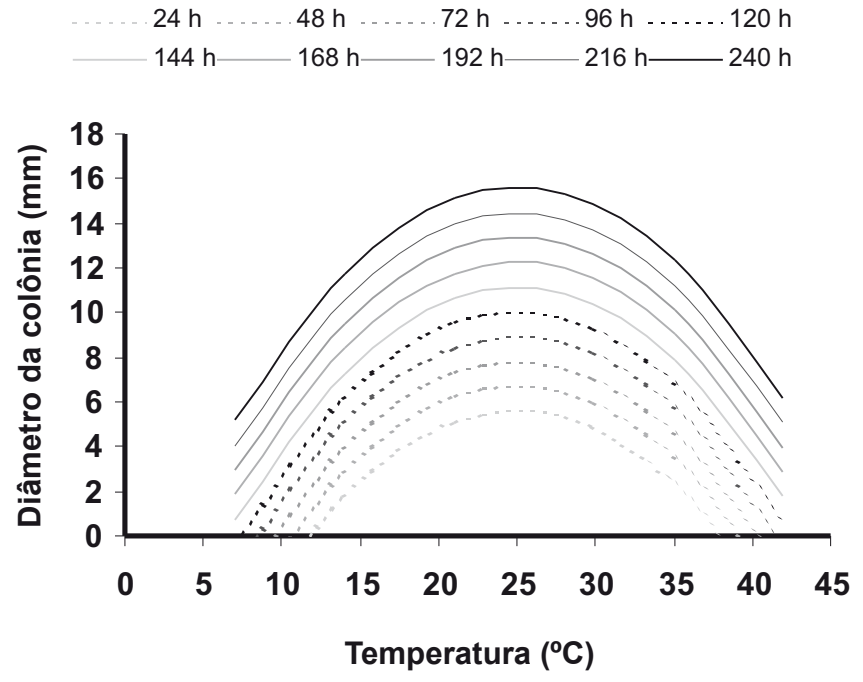

FIG. 1 - Crescimento micelial de Quambalaria eucalypti, em termos de diâmetro da colônia (DC) em BDA em função do tempo (h) e da temperatura $\left({ }^{\circ} \mathrm{C}\right)$ de incubação.

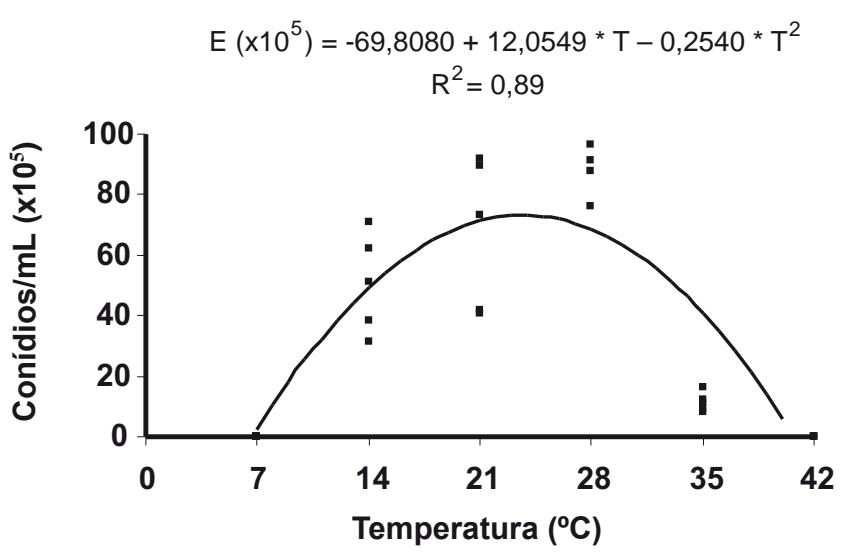

FIG. 2 - Esporulação (conídios/mL x 105) de Quambalaria eucalypti (E) em BDA aos 10 dias de incubação em função da temperatura $(\mathrm{T})$.

\section{Crescimento micelial e esporulação em diferentes meios de cultura}

A interação entre meios de cultura e isolados foi significativa $(\mathrm{p}<0,05)$. De forma geral, os meios de BDA, V8 e CVA proporcionaram maior crescimento micelial após 12 dias de incubação, não havendo diferença entre eles para os três isolados de Q. eucalypti testados (Figura 3). Para esporulação, a interação entre meios de cultura e isolados não foi significativa e o meio de BDA foi o mais favorável à produção de esporos do patógeno (Figura 4).

\section{Efeito da temperatura e do regime de luz sobre a germinação de conídios}

Não houve efeito significativo das temperaturas e dos regimes de luz testados sobre a germinação de conídios. Independentemente da temperatura e do regime 


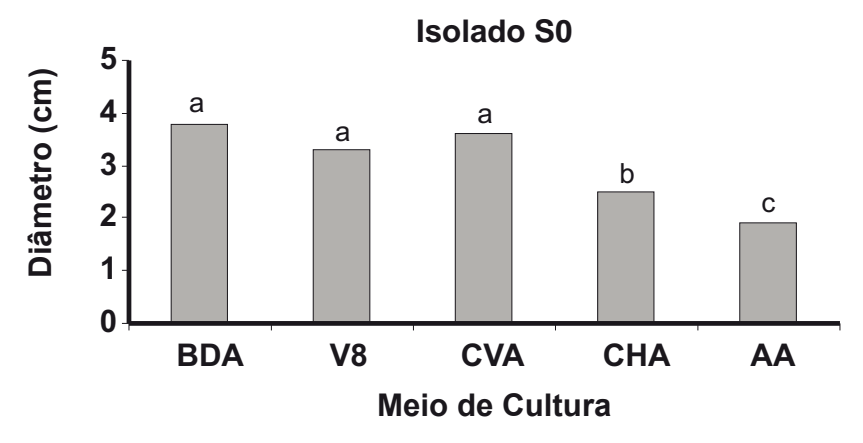

Isolado S8

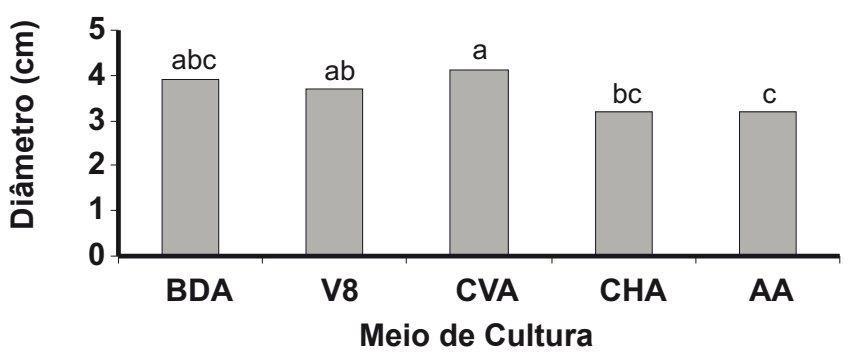

Isolado S25

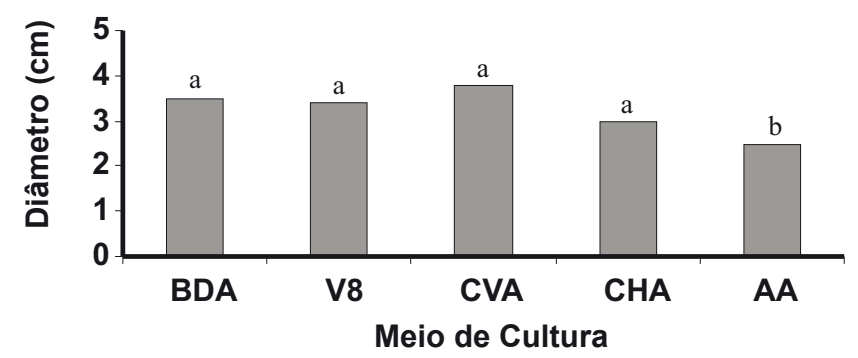

FIG. 3 - Crescimento micelial de três isolados (S0, S8 e S25) de Quambalaria eucalypti, expresso pelo diâmetro das colônias (cm) aos 12 dias de incubação e $28{ }^{\circ} \mathrm{C}$, nos meios BDA, V8, CVA, CHA e AA. Colunas sob a mesma letra não diferem entre si estatisticamente pelo teste de Tukey $(\mathrm{p}<0,05)$. CV $=18,6 \%$

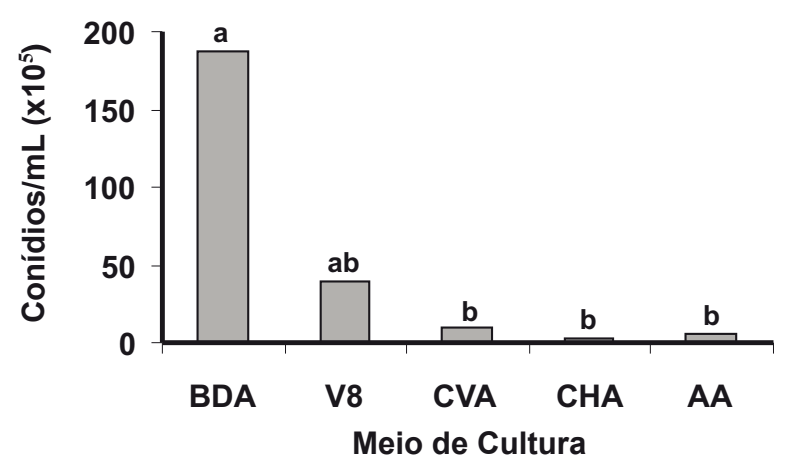

FIG. 4 - Esporulação (conídios/mL x 1055) de Quambalaria eucalypti em função do meio de cultura. Colunas sob a mesma letra não diferem entre si estatisticamente pelo teste de Tukey $(\mathrm{p}<0,05)$. CV $=23,8 \%$ de luz, a taxa média de germinação foi de $85 \%$.

Influência do binômio temperatura-tempo de câmara úmida sobre a severidade da doença

Não houve interação significativa $(p<0,05)$ entre temperatura e tempo de câmaraúmida. Contudo, considerando as temperaturas testadas, observou-se maior severidade da doença a $26^{\circ} \mathrm{C}$. De acordo com o modelo quadrático obtido para explicar a variação da severidade da doença em função da temperatura, estimou-se que a temperatura ótima para infecção foi de $27^{\circ} \mathrm{C}$, com pontos de mínimo e máximo de 13 e $41{ }^{\circ} \mathrm{C}$, respectivamente (Figura 5A). Quanto ao tempo de câmara úmida, observou-se resposta exponencial para a intensidade de doença, sendo que no maior tempo testado (40 h), constataram-se níveis de aproximadamente 40\% de severidade da doença (Figura 5B).

\section{DISCUSSÃO}

A determinação da influência dos fatores do ambiente sobre o cultivo "in vitro" e a infecção de plantas é fundamental para embasar inoculações artificiais (Mueller \& Buck, 2003). Neste estudo, foram caracterizadas, pela
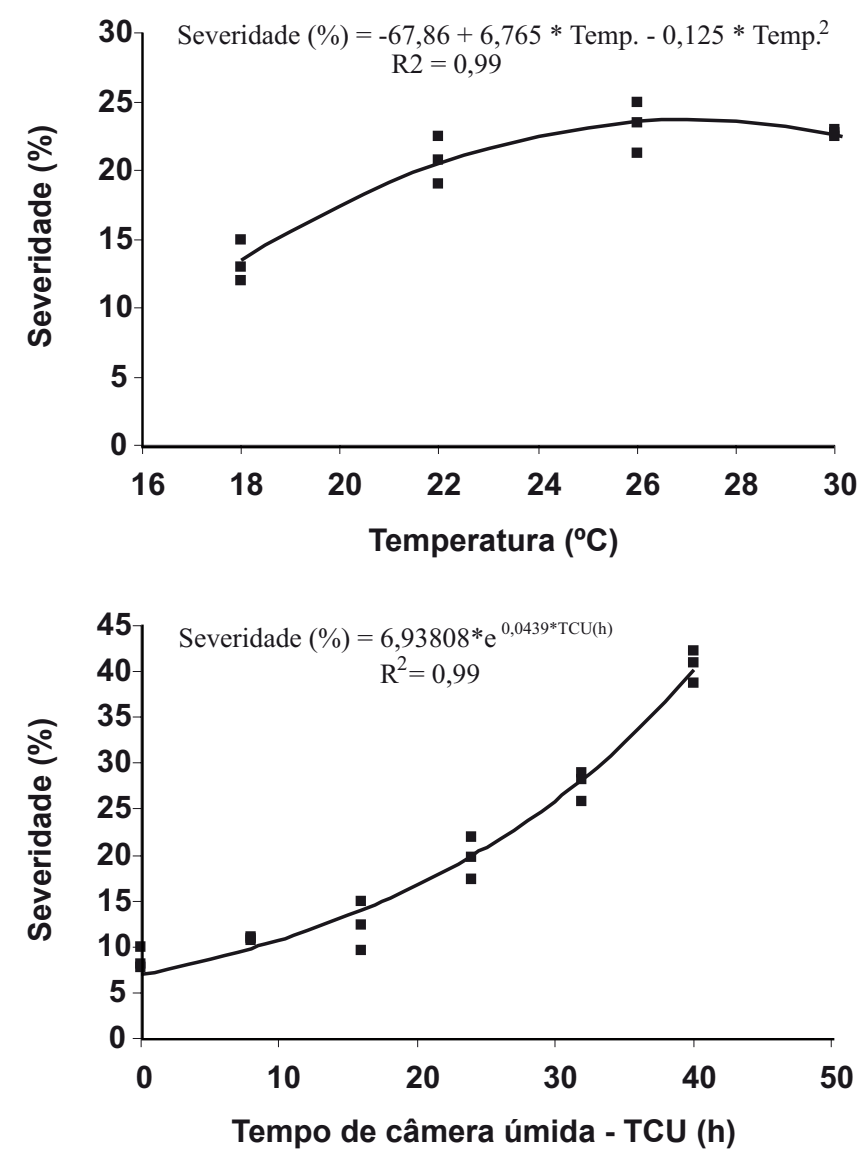

FIG. 5 - Severidade, expressa em \% da área foliar do eucalipto infectada por Quambalaria eucalypti em função da temperatura (A) e do tempo de câmara úmida (B) aos 15 dias de incubação. 
primeira vez, as condições adequadas para multiplicação de inóculo e para a infecção de Q. eucalypti.

O crescimento micelial e a esporulação do patógeno "in vitro" variaram com a temperatura de incubação e com o meio de cultura. Maior quantidade de esporos foi obtida em BDA a $25{ }^{\circ} \mathrm{C}$. O meio V8 (Miller, 1955) propicia o crescimento micelial e a esporulação de vários fungos (Krupinsky, 1982; Piana \& Prestes, 1993; Fernandes \& Santos, 1996), inclusive para aqueles de difícil esporulação (Gonzáles, 1999; Nagel, 1934). Assim como o meio V8, o CVA que engloba uma mistura de caldo de vegetais tem apresentado bons resultados para outros fungos (Pereira $e t$ al., 2003). Para Q. eucalypti, o cultivo in vitro nestes meios não proporcionou maior crescimento e produção de esporos, sendo assim, acredita-se que o cultivo deste patógeno em meio de cultura está de acordo com recomendações de Dhingra \& Sinclair (1995), que preconizam a utilização de meios com menor percentual de nutrientes para estimular a produção de esporos.

A luz, ao contrário do observado para outros patógenos, principalmente no grupo das ferrugens (Tapsoba \& Wilson, 1997; Ruiz et al., 1989), não teve influência sobre a germinação de conídios. Deste modo, as plantas inoculadas artificialmente com $Q$. eucalypti podem permanecer em condições de luminosidade requeridas para o seu pleno desenvolvimento e, conseqüentemente, para expressão máxima do seu nível de resistência.

Sob condições naturais, temperatura, luz e umidade oscilam diuturnamente, mas quando constantes, sob condições artificiais, permitem avaliar o efeito sobre a biologia do patógeno. Os resultados deste trabalho permitem concluir que os processos de infecção e de colonização de $Q$. eucalypti são influenciados pela temperatura e pelo período de molhamento foliar. A temperatura ótima, ou seja, que permitiu maior desenvolvimento da doença, foi estimada em $27{ }^{\circ} \mathrm{C}$. Considerando o sistema atual de produção de mudas de eucalipto por miniestaquia, no qual a condução de minicepas doadoras de propágulos vegetativos para enraizamento ocorre em minijardins clonais, dotados de cobertura e fertirrigação por gotejamento ou inundação temporária (Alfenas et al., 2004), acredita-se que apesar de não haver água livre sobre a superfície foliar, o microclima formado pelas constantes fertirrigações favorecem a infecção de $Q$. eucalypti. Assim, o aumento do espaçamento entre minicepas no minijardim pode constituir uma estratégia de controle da doença. Todavia, é importante salientar que o patógeno, mesmo com $0 \mathrm{~h}$ de molhamento foliar, foi capaz de causar doença, em torno de $6 \%$ de severidade.

$\mathrm{O}$ aumento da severidade da doença em função do incremento do tempo de câmara úmida foliar já foi demonstrado para outros patossistemas (Melching, 1975; Hollier \& King, 1985). Para Q. eucalypti este tipo de resposta pode estar relacionada com a necessidade do patógeno colonizar efetivamente a superfície foliar, conforme observado em um estudo prévio utilizando microscopia de varredura (dados não publicados), antes de iniciar as infecções. Para a ferrugem do milho, causada por Puccinia polysora Underw., maiores severidades da doença foram observadas com $24 \mathrm{~h}$ de molhamento para todas as temperaturas testadas (Godoy et al., 1999), ao passo que para o mal-de-sete-voltas da cebola, a duração do período de molhamento foliar não influenciou a severidade da doença (Carneiro \& Amorim, 1999).

Os resultados obtidos no presente estudo permitem concluir que a multiplicação de inóculo de Q. eucalypti pode ser realizada em meio BDA, o qual é de baixo custo e de fácil preparo, na temperatura de $25^{\circ} \mathrm{C}$ e sob regime de luz de 12 h. Além disso, a infecção e colonização em eucalipto são influenciadas pela temperatura (ótimo $27^{\circ} \mathrm{C}$ ) e período de câmara úmida. A luz não afetou a germinação de conídios, mas observou-se acréscimo exponencial da severidade da doença com o aumento do tempo de câmara úmida. Os resultados obtidos permitem embasar o desenvolvimento de um protocolo de inoculação de eucalipto para avaliação de resistência entre clones e de práticas de controle da doença, que engloba a multiplicação de inóculo de Q. eucalypti e a manutenção das plantas inoculadas sob condições favoráveis à infecção e desenvolvimento dos sintomas. Fornece também subsídios para o manejo integrado da doença e para a análise de risco de epidemia em viveiros clonais de eucalipto.

\section{REFERÊNCIAS BIBLIOGRÁFICAS}

AGRIOS, G.N. Plant Pathology. $5^{\text {th }}$ ed. Amsterdam. Elsevier Academic Press. 2005.

ALFENAS, A.C., ZAUZA, E.Â.V., MAFIA, R.G. \& ASSIS, T.F. Clonagem e doenças do eucalipto. Editora UFV, Viçosa, MG. 2004.

ALFENAS, A.C., ZAUZA, E.A.V., ROSA, O.P.P. \& ASSIS, T.F. Sporothrix eucalypti, um novo patógeno do eucalipto no Brasil. Fitopatologia Brasileira 26:221. 2001.

ANDRADE, G.C.G. Quambalaria eucalypti: Características culturais, infectividade e quantificação da severidade da doença em eucalipto. Dissertação de Mestrado. Viçosa MG. Universidade Federal de Viçosa. 2004.

CARNEIRO, L.C. \& AMORIM, L. Influência da temperatura e do molhamento foliar no monociclo do "mal-de-sete-voltas" da cebola. Fitopatologia Brasileira 24:422-427. 1999.

COLHOUN, J. Effects of environmental factors on plant disease. Annual Review of Phytopathology 11:343-364. 1973.

DHINGRA, O.D. \& SINCLAIR, J.B. Basic plant pathology methods. Boca Raton FL. CRC Press. 1995.

EUCLYDES, R.F. Manual de utilização do programa SAEG (Sistema para Análises Estatística e Genética). Viçosa MG. Universidade Federal de Viçosa. 1997.

FERNANDES, M.C.A. \& SANTOS, S.A. Cultivo de Ampelomyces quisqualis e interferência de fungicidas no seu crescimento in vitro. Fitopatologia Brasileira 21:26-29. 1996.

GODOY, C.V., AMORIM, L. \& BERGAMIN FILHO, A. Influência da duração do molhamento foliar e da temperatura no 
desenvolvimento da ferrugem do milho causada por Puccinia polysora. Fitopatologia Brasileira 24:160-165. 1999.

GONZÁLES, M. Metodología para la manipulation y cultivo in vitro de Micosphaerella fijiensis. Manejo Integrado de Plagas 53:14. 1999.

HOLLIER, C.A. \& KING, S.B. Effect of dew period and temperature on infection of seedling maize plants by Puccinia polysora. Plant Disease 69:219-220. 1985.

KRUPINSKY, J.M. Growth and sporulation of Botryodiplodia hypodermia in response to different agar media and temperatures. Plant Disease 66:481-483. 1982.

MELCHING, J.S. Corn rusts: types, races and destructive potential. Proceedings of the $30^{\text {th }}$ Annual Corn and Sorghum Research Conference. Chicago. 1975. pp. 90-115.

MILLER, P.M. V8 juice agar as general purpose medium for fungi and bacteria. Phytopathology 45:461. 1955.

MUELLER, D.S. \& BUCK, J.W. Effects of light, temperature, and leaf wetness duration on daylily rust. Plant Disease 87:442-445. 2003.

NAGEL, C.M. Conidial production in species of Cercospora in pure culture. Phytopathology 24:1101-1110. 1934.

PEREIRA, J.M, BARRETO, R.W., ELLISON, C.A. \& MAFFIA, L.A. Corynespora cassiicola $\mathrm{f}$. sp. lantanae: a potential biocontrol agent from Brazil for Lantana camara. Biological Control 26:2131. 2003.

PIANA, C.F.B. \& PRESTES, A.M. Esporulação de Stagnospora nodorun em diferentes meios de cultura. Fitopatologia Brasileira 18:512-515. 1993.

RUIZ, R.A.R., ALFENAS, A.C., FERREIRA, F.A. \& RIBEIRO DO VALE, F.X. Influência da temperatura, do tempo de molhamento foliar, fotoperíodo e da intensidade de luz sobre a infecção de Puccinia psidii em eucalipto. Fitopatologia Brasileira 14:51-57. 1989.

TAPSOBA, H. \& WILSON, J.P. Effects of temperature and light on germination of urediniospores os the pearl millet rust pathogen, Puccinia substriata var. indica. Plant Disease 81:1049-1052. 1997.

Recebido 23 Fevereiro 2006 - Aceito 30 Março 2007 - FB 5046 